\title{
The first year
}

\author{
Johannes Attems ${ }^{1}[$
}

Received: 7 December 2019 / Accepted: 7 December 2019 / Published online: 12 December 2019

(c) Springer-Verlag GmbH Germany, part of Springer Nature 2019

In January 2019 I had the great honour to take over as Editor in Chief (EiC) of Acta Neuropathologica (ANP) from Werner Paulus. Of course, it was Werner who had suggested that I would be the right person for the job, otherwise I would not have dared to take over as I seriously doubted that I am up for this challenging task. However, we all know that Werner is always honest and apparently makes the right decisions, how else could one explain his truly remarkable and actually quite unbelievable success with ANP, where he managed to raise the impact factor (IF) from 2.6 when he took over as EiC (IF 2003) to 18.2 (IF 2018). So, how could I have dared to be disobedient and without hesitation I took the leap into the unknown. Well, not entirely unknown, as I co-edited ANPs sister journal Acta Neuropathologica Communications (ANC) together with Werner since 2014, but I knew that ANP has much higher demands. Now, nearly a year later it is about time to briefly reflect on the first year as EiC of ANP.

In 2019 ANP received for the first time in its history well over 1000 submissions and published in print 85 Original Papers, 23 Reviews and 26 Correspondences. The mean time from submission to first decision is currently 10 days and 9 days from acceptance to publication, respectively. The published papers are of the highest quality and well in line with the journals aim "to publish the best papers on pathology of neurological disease, as well as experimental studies on molecular and cellular mechanisms using in vitro and in vivo models, ideally validated by analysis of human tissues." I am delighted to see that the percentage of ANP papers that show both experimental and human data is increasing as I truly believe that major advances can be achieved by a combination of different approaches. In addition, ANP papers should have clinical relevance and it is exciting that ANP papers often directly influence day

Johannes Attems

Johannes.Attems@newcastle.ac.uk

1 Translational and Clinical Research Institute, Newcastle University, Campus for Ageing and Vitality, Newcastle upon Tyne NE4 5PL, UK to day routine diagnostic neuropathology. The longstanding approach of featuring both basic and clinical neuropathological research is a main pillar of ANPs success and therefore I do not plan to make any changes in the journals focus in the foreseeable future.

Given the figures above, e.g., nearly three new submissions per day, you can well imagine that ANP requires a lot of work, not only from myself but also form a large number of colleagues who truly deserve my deepest gratitude; I truly have to thank Werner a lot as he fully supported me in the first 5 months and without his support the transition would certainly not have been so smooth. In fact, I do not think that all authors/ readers even realised that there was a change in $\mathrm{EiC}$ and even to this day some cover letters still begin with "Dear Professor Paulus". Needless to say that Werner still provides his advice whenever I ask for it. Our Editorial Assistant, Lauren Walker, is another person who is crucial to the continuing success of ANP. Lauren fulfils her role with great enthusiasm, competence and efficiency and I am sure that authors are grateful to Lauren for pointing out formal mistakes as ultimately every author prefers that their publication is perfect in every sense, and this includes a correct reference list and other formalities. In addition, I am truly grateful to the other Js, Jeroen Hoozemans and Jason Huse, who bravely took over the role of EiC of ANC nearly immediately after I asked them in January 2019. We are in close contact thereby ensuring that ANP and ANC are truly sister journals and they always provide their valuable advice when I need it. The same is true for the many members of the ANP Editorial Board; it is a privilege that I can rely on these colleagues who together represent the strongest expertise, which covers all sub-specialities of Neuropathology (and beyond) and I am truly grateful for their support. Next to be thanked are the numerous reviewers who sacrifice their valuable time to perform excellent reviews and (usually) submit them in due time. Of course the authors have to be thanked as well, as it is them who actually "write" the journal. The Springer team deserves credit; Melissa Ramondetta, the Executive Editor fully supported me right from the start and the Production team led by Anburaj Sundaram is responsible 
for the very fast turnaround time of accepted articles so that you, the reader, can actually read them only a few days after the manuscripts have been accepted. Naturally, I am very grateful to you too, without interested researchers there would be no need for our journal. I am aware, that this was quite an extensive thanks list, but I hope it reflects my honest feeling that the success of ANP certainly relies on the combined efforts of many colleagues and therefore ANP is certainly not my journal but our journal! It is my privilege and honour to serve ANP as the person who tries his best to channel all those individual efforts with the aim to publish an internationally important top journal that is made by Academics for Academics!

I would also like to apologise to all those authors whose manuscripts were rejected, either straight away or after review. Please rest assured that I did not mean any disrespect and truly valued your submission. However, ANP is a print journal with limited space available and therefore I currently have to reject about $90 \%$ of submission. Yes, that's true $90 \%$ ! Believe me, rejecting between one and three papers every day is not a joyful experience and is not something that is done lightly but nevertheless, it has to be done. The least I can do to mitigate the frustration of rejection is not to waste the time of authors by either letting them wait for days or even weeks until they receive a decision "Reject without Review" or by inviting multiple revisions only to finally reject the paper because one reviewer is still not fully satisfied and feels that the manuscript is just not as good as it could be in an ideal world.

In the past year, I have certainly learned a lot and could write many more pages about this experience, but fear not. I will stop now and invite you to read yet another exciting issue of ANP. Please continue to support our Acta so we can all look positively forward to 2020 and beyond!

Publisher's Note Springer Nature remains neutral with regard to jurisdictional claims in published maps and institutional affiliations. 